Mater. Res. Soc. Symp. Proc. Vol. 1475 @ 2012 Materials Research Society

DOI: 10.1557/opl.2012.617

\title{
Copper Corrosion in Aqueous Sulfide Solutions under Nuclear Waste Repository Conditions
}

\author{
J. Chen, Z. Qin and D. W. Shoesmith \\ Department of Chemistry, The University of Western Ontario \\ London, Ontario, N6A 5B7, Canada
}

\begin{abstract}
The corrosion behavior of oxygen-free copper in anoxic sulfide solutions under nuclear waste disposal conditions was studied using electrochemical impedance spectroscopy (EIS), scanning electron microscopy (SEM) equipped with a focused ion beam (FIB), X-ray photoelectron spectroscopy (XPS) and Micro X-ray diffraction ( $\mu$ XRD). The film growth process and mechanism were elucidated using an Au marker test, and the contribution of solution diffusion to corrosion was demonstrated in magnetically-stirred experiments. The effect of groundwater chemistry, particularly chloride content on copper corrosion and film properties was characterized using long-term corrosion experiments.
\end{abstract}

\section{INTRODUCTION}

The selection of copper for the fabrication of nuclear waste containers is based on its thermodynamic stability in the anaerobic saline groundwaters anticipated in Swedish/Finnish/ Canadian nuclear waste repositories. The only potential oxidant able to drive the corrosion of copper is expected to be sulfide $\left(\mathrm{SH}^{-}\right)$present in groundwater containing chloride due to either mineral dissolution or microbial production from sulfates. It is also known that the concentration of chloride influences the properties of sulfide films formed on copper surfaces when the solution contains both sulfide and chloride [1]. However, the synergistic effects of sulfide and chloride on the mechanism of film growth and film properties remain unresolved.

In this paper, we present results on the film growth process and mechanism on copper surfaces using long-term experiments and a marker test. Our primary goal was to determine the nature of the rate controlling step in the overall corrosion reaction and whether or not it changed as sulfide films developed. Of key importance is whether or not the corrosion process will, over extended exposure times, be changed or controlled by the properties of the copper sulfide film when the groundwater chemistry changes.

\section{EXPERIMENTAL}

Phosphorous-doped (40-60 ppm), oxygen-free copper (Cu-OF) provided by the Swedish Nuclear Fuel and Waste Management Co. (SKB), Stockholm, Sweden was used in all experiments. Working electrodes were copper disks, with a diameter of $1 \mathrm{~cm}$, threaded into a 
stainless steel shaft. Non-conductive lacquer was painted on the sample to prevent contact of the $\mathrm{Cu} /$ steel junction with the aqueous electrolyte. After painting, electrodes were heated at $60^{\circ} \mathrm{C}$ for $12 \mathrm{~h}$ to promote adhesion between the paint and the sample. $\mathrm{Cu}$ surfaces were polished successively with $240,600,800,1000,1200$ grade $\mathrm{SiC}$ paper and then to a mirror finish using 1 $\mu \mathrm{m}, 3000 \AA$, and $500 \AA \mathrm{Al}_{2} \mathrm{O}_{3}$ suspensions. Prior to experiments, electrodes were washed with deionized Millipore water $(18.2 \mathrm{M} \Omega \cdot \mathrm{cm})$, ultrasonically cleaned in methanol, washed again with deionized water, and finally dried using argon gas.

All experiments were performed in an Ar-purged anaerobic chamber (Canadian Vacuum Systems Ltd.), maintained at a positive pressure (2-4 mbar) by an MBraun glove box control system, to ensure anoxic conditions were maintained ( $\left.\mathrm{c}_{\mathrm{O} 2}<1 \mathrm{ppm}\right)$. The oxygen concentration in the chamber was analyzed with an MBraun oxygen probe. The sulfide solutions used were prepared with deionized Millipore water $(18.2 \mathrm{M} \Omega \cdot \mathrm{cm})$, reagent-grade sodium sulfide $\left(\mathrm{Na}_{2} \mathrm{~S} \cdot 9 \mathrm{H}_{2} \mathrm{O}, 98.0 \%\right.$ assay), and analytical-grade sodium chloride $(\mathrm{NaCl}, 99.0 \%$ assay).

Electrodes were immersed in sulfide solution (1L) for various times under natural corrosion conditions. A standard three-electrode system was employed with a Pt plate as the counter electrode and a saturated calomel electrode (SCE) as the reference electrode. All potentials are quoted on this scale. Prior to each experiment, electrodes were cathodically cleaned at -1.6 $\mathrm{V} / \mathrm{SCE}$ for $2 \mathrm{~min}$, and then at $-1.15 \mathrm{~V} / \mathrm{SCE}$ for $2 \mathrm{~min}$. The corrosion potential ( $\mathrm{E}_{\mathrm{CORR}}$ ) was monitored throughout each experiment and electrochemical impedance spectroscopy (EIS) measurements were performed intermittently.

Experiments were performed at ambient temperature, $22 \pm 2^{\circ} \mathrm{C}$. The EIS measurements were made over the frequency range $10^{5}$ to $10^{-3} \mathrm{~Hz}$ using a Solartron 1287 electrochemical interface and a Solartron 1255B frequency response analyzer. The validity of impedance spectra was checked using the Kramers-Krönig transform. The experimental procedure has been described in detailed previously [2].

Electrodes removed from solution for surface analyses were rinsed with deionized water for 10 minutes and dried with cold Ar gas. Analyses were then performed immediately with the minimum period of interim storage. The surface and cross-sectional morphologies of corroded specimens were observed using a Leo 1540 FIB/SEM microscope (Zeiss Nano Technology Systems Division, Germany). The composition of sulfide films was qualitatively analyzed by Energy Dispersive X-ray analysis (EDS) using a Leo 1540 FIB/SEM microscope. X-ray photoelectron spectroscopy (XPS) was carried out using an SSX-100 spectrometer. The X-ray source was the K $\alpha$ peak of Al. A Bruker D8 Discover Micro X-ray diffractometer ( $\mu$ XRD) was used to determine the corrosion products formed on the copper samples.

\section{RESULTS AND DISCUSSION}

\section{Sulfide film growth mechanism}

In our previous work [2], the corrosion product formed on a copper surface corroded in anoxic $0.1 \mathrm{M} \mathrm{NaCl}+5 \times 10^{-4} \mathrm{M} \mathrm{Na}_{2} \mathrm{~S}$ solution was shown to be a compact, single layer $\mathrm{Cu}_{2} \mathrm{~S}$ film. 
Its growth obeyed a parabolic law, suggesting a diffusion-controlled process. The controlling factor for film growth could be either $\mathrm{Cu}^{+}$diffusion in the film or $\mathrm{SH}^{-}$diffusion in the solution and/or the film. To identify the film growth mechanism, a marker test was performed on a $\mathrm{Cu}$ specimen. The specimen was first immersed in a sulfide solution for $161 \mathrm{~h}$ to form a thin sulfide film. The specimen was then removed and a gold line with a width of $200 \mu \mathrm{m}$ sputter-deposited on top of the $\mathrm{Cu}_{2} \mathrm{~S}$ film. The marked sample was then re-immersed in the same solution for a further $1530 \mathrm{~h}$.

If the film growth process is an inward growth mechanism controlled by $\mathrm{SH}^{-}$diffusion through the film, further film growth would occur under the Au layer which would remain on top of the surface as corrosion continued. However, if film growth proceeded by an outward growth mechanism controlled by $\mathrm{Cu}^{+}$diffusion through the film or by a combination of $\mathrm{Cu}^{+}$diffusion in the film and $\mathrm{SH}^{-}$diffusion from bulk solution to the film/solution interface, continued film growth after re-immersion would bury the marker. Moreover, the thickness of the film below the marker would show no significant change.

Figure 1 shows the cross sectional morphologies of the marked specimen (prepared by FIB) observed using backscattered electron detection. It is clear that the Au marker was buried in the film and that the thickness of the film below the Au marker remained at $200 \mathrm{~nm}$; i.e., similar to the thickness of the pre-formed film. This indicates that the film growth involves an outward growth mechanism controlled by either $\mathrm{Cu}^{+}$diffusion in the film or a combination of $\mathrm{Cu}^{+}$ diffusion in the film and $\mathrm{SH}^{-}$diffusion in the solution.

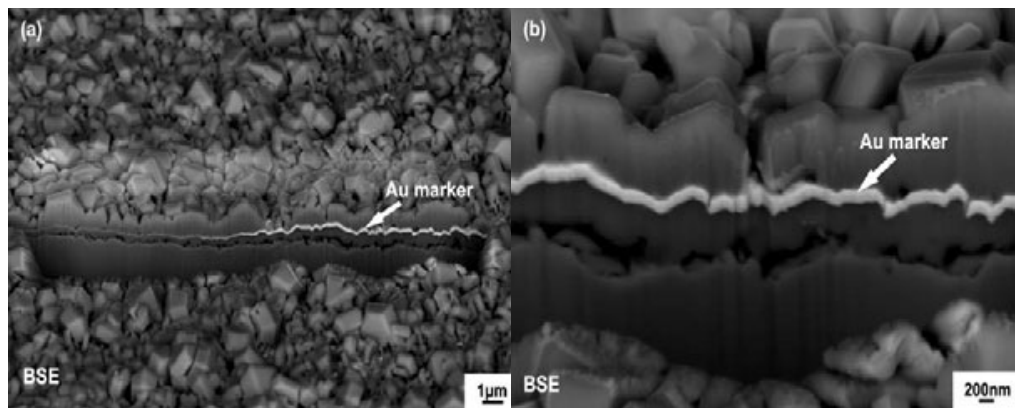

Figure 1. Cross-sectional morphologies of oxygen-free copper cut using FIB after immersion in $0.1 \mathrm{M} \mathrm{NaCl}+5 \times 10^{-4} \mathrm{M} \mathrm{Na}_{2} \mathrm{~S}$ solution for $161 \mathrm{~h}$ prior to deposition of the Au marker and for a further $1530 \mathrm{~h}$ afterwards.

\section{Evidence of the effect of solution diffusion}

Our previous EIS analyses indicated that $\mathrm{SH}^{-}$diffusion in solution is also partially controlling the film growth [2]. However, direct experimental evidence is required to determine the extent of $\mathrm{SH}^{-}$diffusion in solution to film growth, and how this influences the sulfide film properties. To 
investigate these influences experiments were performed in magnetically-stirred solutions.

To avoid film erosion, specimens were first immersed in stagnant solution for 7 days and the evolution of $\mathrm{E}_{\mathrm{CORR}}$ monitored. During this period, growth of an adherent $\mathrm{Cu}_{2} \mathrm{~S}$ film commenced. The solutions were then magnetically stirred for $3 \mathrm{~h}$ at a constant rate $(80 \mathrm{rpm})$, after which an EIS measurement was made. Subsequently, the solution stirring was stopped and film growth allowed to proceed further under stagnant conditions. This procedure was repeated until the total immersion time reached $1691 \mathrm{~h}$. With the specimen immersed in stagnant solution, $\mathrm{E}_{\mathrm{CORR}}$ stabilized around $-0.88 \mathrm{~V} / \mathrm{SCE}$, but during stirring, decreased to $-0.91 \mathrm{~V} / \mathrm{SCE}$, indicating an increased flux of $\mathrm{SH}^{-}$to the film/solution interface [1]. After 1691h of immersion, the film was cross sectioned and the morphology is shown in Figure 2. The morphology of a second specimen not subject to stirring is also shown. When the solution was stirred magnetically, the film adopted a rod-like structure with an average thickness of $800 \mathrm{~nm}$. This is thicker than the average thickness of $700 \mathrm{~nm}$ obtained for films grown in stagnant solutions which are comprised of polyhedral crystals. This provides direct experimental evidence that the flux of $\mathrm{SH}^{-}$in solution has a considerable influence on film growth kinetics and film morphology.

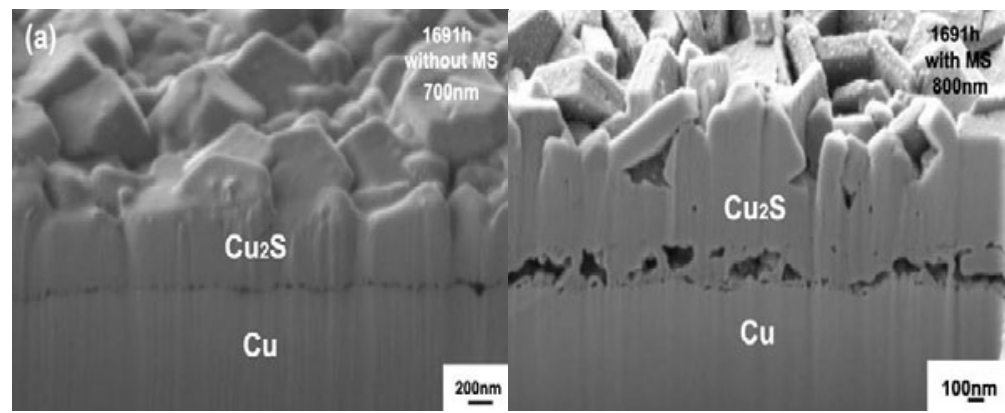

Figure 2. Cross-sectional morphologies of oxygen-free copper after immersion in $0.1 \mathrm{M}$ $\mathrm{NaCl}+5 \times 10^{-4} \mathrm{M} \mathrm{Na}_{2} \mathrm{~S}$ solution for $1691 \mathrm{~h}$ : (a) without magnetic stirring; and (b) with intermittent magnetic stirring.

\section{$\underline{\text { Effect of sulfide concentration on Cu corrosion and film properties }}$}

We have been characterizing the properties of sulfide films on copper surfaces under natural corrosion conditions using $\mathrm{E}_{\mathrm{CORR}}$ measurements, EIS, SEM or FIB cross-sectioned corroded specimens, XPS, and $\mu$ XRD. Experiments are being conducted in anaerobic sodium chloride solutions $(0.1 \mathrm{~mol} / \mathrm{L})$ containing various concentrations of sulfide for exposure periods up to 4000 hours ( $\sim 167$ days). The corrosion product is a single layer $\mathrm{Cu}_{2} \mathrm{~S}$ film whose growth kinetics varies with sulfide concentration. When the concentration is low $\left(5 \times 10^{-5} \mathrm{~mol} / \mathrm{L}\right)$ the film appears cellular and its thickness $(\mathrm{d})$ increases linearly $(\mathrm{d}=\mathrm{At})$ with immersion time $(\mathrm{t})$, Figure 3. The film growth process is controlled primarily by $\mathrm{SH}^{-}$diffusion in aqueous solution, implying 
that the sulfide film is not protective under these conditions up to this exposure time $[3,4]$. However, when the sulfide concentration is $\geq 5 \times 10^{-4} \mathrm{~mol} / \mathrm{L}$, the film appears compact, and its growth obeys a parabolic law, $\mathrm{d}=\mathrm{At}^{\mathrm{n}}$, Figure 3 . A can be taken to be the initial corrosion rate, and $\mathrm{n}$, usually in a range of 0.5 to 1.0 , as an indicator of the protectiveness of the corrosion products formed. The lower the value of $n$, the more protective the sulfide film is to corrosion [2]. As a consequence, in solutions with higher sulfide concentration such as $1 \times 10^{-3} \mathrm{~mol} / \mathrm{L}$, film growth is controlled mainly by $\mathrm{Cu}^{+}$diffusion in the sulfide film, which is protective under these conditions $[2,4]$. Since the film properties change with sulfide concentration; for example, a porous film is formed when the sulfide concentration in the solution is reduced to $5 \times 10^{-5} \mathrm{~mol} / \mathrm{L}$, it is somewhat arbitrary to equate the film growth rate to the corrosion rate of copper.

By fitting EIS spectra to appropriate equivalent circuit models a diffusion coefficient for $\mathrm{Cu}^{+}$ in the sulfide film of $\sim 10^{-10} \mathrm{~cm}^{2} / \mathrm{s}$ was obtained [2]. This value is considerably lower than the anticipated diffusion coefficient for $\mathrm{SH}^{-}$in compacted clay buffer $\left(\sim 10^{-7} \mathrm{~cm}^{2} / \mathrm{s}\right.$ [5]). Therefore, for these conditions, the overall corrosion rate could be limited by film properties not those of the compacted buffer that would be packed around the container in a disposal repository.

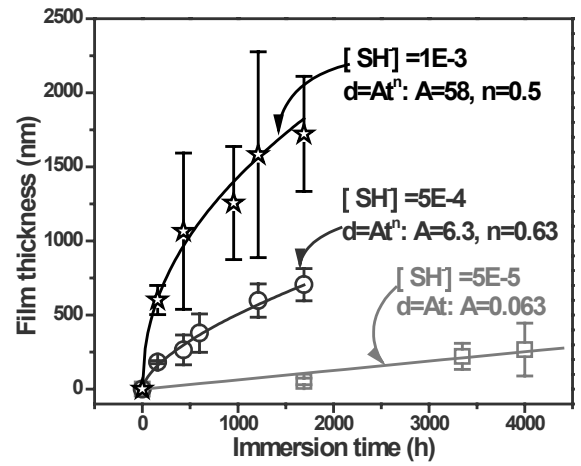

Figure 3. Film growth kinetics of $\mathrm{Cu}$ in sulfide solutions with different concentrations.

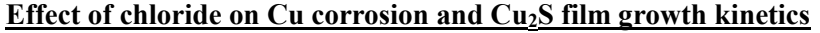

Experiments are being conducted in anaerobic sodium sulfide solutions $\left(10^{-3} \mathrm{~mol} / \mathrm{L}\right)$ containing various concentrations of chloride for exposure periods up to 3000 hours ( $\sim 125$ days).

The corrosion product is always a single layer $\mathrm{Cu}_{2} \mathrm{~S}$ film. When the chloride concentration is low $(0.1 \mathrm{~mol} / \mathrm{L})$, the film appears compact and its growth obeys a parabolic law. The film growth process is controlled mainly by $\mathrm{Cu}^{+}$diffusion in the sulfide film indicating the film is protective under these conditions. When the chloride concentration is increased to $0.5 \mathrm{~mol} / \mathrm{L}$, EIS spectra 
exhibit as many as three time constants. The high frequency response implies that some fast localized corrosion process may be occurring on the copper surface, although no obvious pits are observed, the high frequency response being attributable to the interfacial charge transfer process occurring on exposed $\mathrm{Cu}$ surface locations.

EIS spectra fitted to the equivalent circuits previously developed [2-4] yield a diffusion coefficient for $\mathrm{Cu}^{+}$in the sulfide film of $\sim 10^{-10} \mathrm{~cm}^{2} / \mathrm{s}$ which is similar to that obtained in 0.1 $\mathrm{mol} / \mathrm{L}$ chloride solutions. This suggests that, for these conditions, film properties would still be the limiting factor for the overall corrosion rate. Whether or not a similar corrosion limitation would be exerted at higher chloride concentrations is presently under investigation, and whether or not pitting corrosion occurs at higher chloride concentrations remains to be determined.

\section{CONCLUSIONS}

1) The corrosion product formed on copper in anoxic sulfide solutions is a single layer $\mathrm{Cu}_{2} \mathrm{~S}$ film, and the film growth is via an outward growth mechanism;

2) When the $\mathrm{SH}^{-}$concentration is low $\left(5 \times 10^{-5} \mathrm{~mol} / \mathrm{L}\right)$ the film appears cellular and its thickness increases linearly with immersion time. Film growth is controlled primarily by $\mathrm{SH}^{-}$diffusion in aqueous solution, implying that the film is not protective under these conditions up to this exposure time. When the $\mathrm{SH}^{-}$concentration is $\geq 5 \times 10^{-4} \mathrm{~mol} / \mathrm{L}$, the sulfide film appears compact and its growth obeys a parabolic law. In this case, film growth is controlled mainly by $\mathrm{Cu}^{+}$diffusion in the sulfide film indicating the film is protective under these conditions. $\mathrm{SH}^{-}$diffusion in solution also contributes to the copper corrosion process.

3) The diffusion coefficient of $\mathrm{Cu}^{+}$in the $\mathrm{Cu}_{2} \mathrm{~S}$ film is $\sim 10^{-10} \mathrm{~cm}^{2} / \mathrm{s}$, consistent with the published values measured on $\mathrm{Cu}_{2} \mathrm{~S}$-type phases.

\section{ACKNOWLEDGEMENT}

This research was funded by the Swedish Nuclear Fuel and Waste Management Co. (SKB, Stockholm, Sweden). The authors would like to thank Ms. S.D. Pretty and Dr. D. Zagidulin for their help with XRD and XPS measurements, respectively.

\section{REFERENCES}

1. J. M. Smith, Ph.D Thesis (The University of Western Ontario, 2007).

2. J. Chen, Z. Qin and D.W. Shoesmith, J. Electrochem. Soc. 157 (10), C338-C345 (2010).

3. J. Chen, Z. Qin and D.W. Shoesmith, Electrochim. Acta, 56, 7854-7861(2011).

4. J. Chen, Z. Qin and D.W. Shoesmith, Corros. Eng. Sci. Tech. 46 (2), 138-141 (2011).

5. SKB Swedish Nuclear Fuel \& Waste Management Co., "Long-term Safety for KBS-3

Repositories at Forsmark and Laxemar-a First Evaluation - Main Report of the SR-Can

Project”, SKB Technical Report, TR-06-09 (2006). 